\title{
UN SIGLO HA. AÑO EXCEPCIONAL. IMPORTANTES PUBLICACIONES EN «ARCHIVOS». UN ESTUDIANTE DE MEDICINA GOLEA AL BARCA
}

\begin{abstract}
ARRUGA A ${ }^{1}$
1905. Tricentenario del Quijote. Atentado frustrado contra Alfonso XIII en París. Luego el rey viaja a Londres: ¿Viaje matrimonial? Se barajan los nombres de las princesas de Connaught y Battemberg. Primer tomo del «Espasa».

Gonin publica en «Archivos» sobre el rol del vítreo en el desprendimiento de la retina, presagio de decisivas aportaciones futuras. Pérez-Bufill un estudio sobre embriología del ojo. Ponencia de Menacho sobre «Cuerpos extraños intraoculares». También describió interesantes métodos de exploración: Radiografía estereoscópica y «diplógrafo» para examinar la diplopía. Lagrange publica un caso de actinomicosis lagrimal y un caso de quiste hidatídico retrobulbar con ablación exitosa y conservación del ojo. Santos Fernández comenta sobre dificultades en el diagnóstico del glaucoma por el incoherente comportamiento de la pupila. También describe un caso de desprendimiento total congénito en dos hermanos. Castresana dedica un extenso trabajo a la congestión papilo-retiniana activa.

Márquez publica un raro caso de afección corneal, zona oftálmico, lesión de las capas posteriores de la córnea y ectasia consecutiva de las anteriores y revisa la literatura sobre complicaciones inusuales del zona oftálmico.

Tomás Blanco hace un extenso estudio sobre las relaciones entre las enfermedades del aparato audi-

tivo y las de la visión. Henri Copes publica dos casos de coroiditis diseminada simpática a la vez que comenta 8 casos aparecidos en la literatura entre 1882 y 1902.

Lagleyze describe un método original de tratamiento del entropión triquiasis.

Además de los trabajos citados en tomo de 1905 de «Archivos», contiene numerosos artículos y comentarios sobre casos clínicos interesantes así como extractos de las contribuciones más importantes en congresos extranjeros, cuya sola enumeración excedería el ámbito de estas líneas.

Pero permítaseme recordar que el 2 de abril de 1905 se enfrentaban en un partido de segunda vuelta del Campeonato de Cataluña (1) el F. C. Barcelona y F. C. Català: Ganó el Català por $1 \mathrm{a} 4, \mathrm{y}$ uno de los goleadores era el interior izquierdo, un estudiante de tercero de Medicina llamado Hermenegildo Arruga.

\section{NOTAS}

1. Lejos la época de los fichajes multimillonarios, los jugadores no sólo no percibían nada sino que contribuían con unos céntimos para pagar a los hombres que marcaban las líneas del campo y colocaban las redes. En más de una ocasión tuvo que interrumpirse el partido pues si se reventaba el balón no había otro para sustituirlo.
\end{abstract}

\footnotetext{
1 Doctor en Medicina.

E-mail: alberto_ac20@hotmail.com
} 